First, pragmatism. I think there are many versions of pragmatism, or ways of thinking that call themselves pragmatic. If, as James Hoff suggests, I am a pragmatist, I would put myself closer to Charles Peirce than to William James. But the real issue, I think, is whether neopragmatism, as embodied in the writing of Richard Rorty, Stanley Fish, and others, allows for the possibility of persuasion based on an appeal to principles. That is, do we believe what we believe only because we were born (or interpellated, if you like) into some interpretive community (or ideological system) or because we have reasonable grounds for connecting our beliefs to the world?

Is it enough, for example, to say of slavery that it doesn't work, or do we need to say that it is, in some way, wrong? Our social and political structures are based on principles, and my fear is that, for fundamentalists, the principles need no interpretation and that, for pragmatists, there are no principles. James Hoff says that pragmatism "relies on a set of principles and beliefs that are constantly subject to critique and change but that are held with no less passion, conviction, and appreciation" than those I might profess myself.

Well, that does sound like pragmatism to me: principles that are not really principles. If, by principle, we mean something like this definition from the $O E D$ - "a fundamental source from which something proceeds; a primary element, force, or law which produces or determines particular results; the ultimate basis upon which the existence of something depends; cause, in the widest sense"-then I would suggest that they ought to be held not with passion but with reason and that they ought not to be subject to change. They may need to be interpreted to suit new situations, but they are indeed fundamental. And that is why I would situate the humanities between fundamentalism, which denies the need for interpretation, and pragmatism, which denies any fixed belief in the first place.

As to the lesser issue of whether neopragmatists opposed deconstruction, I could be wrong about this, but I seem to remember arguments against theory in general coming from critics who claimed to be pragmatists. And, of course, I had my own reservations about deconstructive thought. But the question of whether deconstruction has fixed principles is indeed an interesting one-and well beyond the scope of this discussion.

Turning to Harold Fromm's comments, I cannot accept his argument as I understand it. What does it imply, for instance, to say that language is a "recently acquired capacity"? Did culture, as we understand it, precede or follow language? And does the precedence matter? Yes, we were natural for eons before we were cultural-before we were human, even-but so what? We are cultural now, and culture is the domain of the humanities. To the extent that culture is, to use Harold Fromm's terminology, a machine, it is that machine we must understand, and language is the engine driving that machine. The relation between signs and the world, between signs and the self, and the history of those relations-these are our domain.

I call that domain textuality, and I cite the old trivium as a way of organizing that domain for study in schools, meaning, specifically, the study of language as a system (the old grammar), the study of the relation between language and reasoning (the old logic), and the study of the relation between language and emotion (the old rhetoric). If we can resituate these at the center of our activities, we will not merely be raising a tattered ensign but rebuilding the ship itself while it is still floating. Not easy, but possible and necessary.

Robert Scholes Brown University

\section{The Chinese Renaissance and the Vernacular}

\section{To THE EDITOR:}

These notes are inspired by Gang Zhou's highly apposite "The Chinese Renaissance: A Transcultural Reading" (120 [2005]: 783-95), in which Zhou refers to "Hu's misrepresentation of the Renaissance narrative" (791). I hope I may be permitted to sharpen her criticism by foregrounding the baneful effect Hu Shi's mistaken views had on the course of China's literary history.

One major error is Hu Shi's equating his concept of vernacular with Dante's. The Italian poet's definition of "vernacular" is specific and clear: "that which children learn from those around them, when they first begin to distinguish words, 
or, more briefly, that which we acquire without any rules, by imitating our nurses." In contrast to Dante's contemporary spoken language, $\mathrm{Hu}$ Shi distinguished two traditional styles of written Chinese, the wenyan 'literary language' of the third century BC to $589 \mathrm{AD}$ and the baihua 'plain speech' style, which goes back to the Tang dynasty (618-907). He advised writers to follow the style of Water Margin and Journey to the West, two so-called vernacular works of the Ming dynasty (1368-1644), a suggestion equivalent to asking modern writers to eschew Arthurian English and write in Shakespearean English. And his fixation on written language is poles apart from Dante's direct identification of the vernacular with actual spoken language, as is further borne out by Dante's meticulous attention to the social, educational, and dialectical variations in the speech of the subjects in the Divine Comedy.

While it is true that Hu Shi made a portentous blunder in considering baihua a vernacular comparable to Italian, in his own writing he hewed to a style that was close to speech. But from his time right down to the present, the overwhelming preponderance of academic, journalistic, and general writing has been in a deeply entrenched ban bai ban wen 'half vernacular, half literary' style, which Patrick Hanan correctly designates as "mixed" and "intermediate" and in which classical and vernacular can be combined, even in the same sentence-in short, a truly hybrid style of writing that is readily fostered by the Chinese character script.

Hu Shi expressed surprise that after his call for writing reform the "vernacular" replaced the literary style as the "national language" within a matter of five short years. Zhou rightly chides $\mathrm{Hu}$ Shi for his failure to recognize the long timemeasured in centuries-that it took for Italian to replace Latin in all spheres of life, especially the academic. The fact of the matter is that $\mathrm{Hu}$ Shi made the wrong comparison. The comparison is not writing in Italian versus writing in Chinese in the misnamed "vernacular" style. It should be Italian written in an alphabetic script versus Chinese also written in an alphabetic script.

When $\mathrm{Hu}$ Shi began championing vernacular writing, he had to contend with a rival group of reformers who sought a more sweeping change- one that would see Chinese characters replaced by an alphabetic script. Hu Shi responded, "I think that in the future we should use a phonetic script. However ... we must first use a vernacular written language [wenzi] to replace the literary script." But after the swift ascendancy of the hybrid style, made possible by his success in deflecting the course of China's literary history, Hu Shi apparently gave no further thought to the alphabetic writing of Chinese.

Nor, owing to nationalistic and elitist influences, have most Chinese, despite the advocacy of such prominent figures as Mao Zedong; Lu Xun, China's greatest writer of the twentieth century; Mao Dun, China's foremost novelist and onetime minister of culture; and Wang Li and Lü Shuxiang, two of China's leading linguists-and of a small group of Chinese and Western scholars, some of whom, bearing in mind the centuries-long transition from Latin to Italian, have a long-range view of the once bitterly contested problem of wenzi gaige 'script reform.' (Documentation for the above notes is available in my "The Chinese Renaissance: A Reassessment" [Bulletin of Concerned Asian Scholars 17.4 (1985): 52-63] and The Chinese Language: Fact and Fantasy [U of Hawaii P, 1984].)

\section{John DeFrancis \\ University of Hawai' i, Mānoa}

\section{Reply:}

I am grateful to John DeFrancis for his comments on my essay about Hu Shi's creative uses of the European Renaissance and promotion of a Chinese Renaissance. DeFrancis rightfully points out that when Hu Shi began his advocacy of the vernacular, he had to contend with a rival group of reformers who would have replaced Chinese characters with an alphabetic script. In other words, Hu Shi's vernacular was only one of the solutions that Chinese intellectuals imagined for the linguistic and cultural challenges they faced at the time. One wonders what a Chinese Renaissance would have been, had the more radical approach won the battle.

I tend to argue in defense of $\mathrm{Hu}$ Shi in his considering baihua a vernacular system comparable to Italian. DeFrancis astutely points out that $\mathrm{Hu}$ Shi's concept of vernacular is different from 